\title{
The Improvement of Intelligibility in the Oral Production of Standard English: A Study About the Production of Vowel Quality in Stressed and Unstressed Syllables
}

\author{
Ana María Muñoz Mallén ${ }^{1} \&$ Víctor Pavón Vázquez ${ }^{2}$ \\ ${ }^{1}$ Teacher Training College "Sagrado Corazón", affiliated to the University of Córdoba, Córdoba, Spain \\ ${ }^{2}$ The University of Córdoba, Córdoba, Spain \\ Correspondence: Ana María Muñoz Mallén, Teacher Training College "Sagrado Corazón", University of \\ Córdoba, Spain, Córdoba, Spain.
}

\author{
Received: February 20, 2019 Accepted: March 13, 2019 Online Published: March 16, 2019 \\ doi: 10.5539/elt.v12n4p115 URL: https://doi.org/10.5539/elt.v12n4p115
}

\begin{abstract}
Pronunciation is an essential aspect in the teaching of the English language, especially those aspects of pronunciation such as stress and vowel quality as they are crucial elements to ensure intelligibility in communication. The general objective of this study is to investigate whether the theoretical-practical instruction on pronunciation has a crucial impact on the vowel quality production of stressed and unstressed syllable in isolated words and in wider contexts, and therefore, in the improvement of intelligibility and of the oral production in general terms, in two groups of Spanish students of English (the control and the experimental group). More particularly, the study addresses the impact of formal instruction in pronunciation based on deduction in terms of rule formation from a cognitive perspective. The results indicate that the specific work implemented with the production of vowel quality in stressed and unstressed syllables have a significant impact on intelligibility.
\end{abstract}

Keywords: pronunciation, intelligibility, instruction, stress, vowel quality.

\section{Introduction}

Pronunciation is an integral element of oral communication and it should not be treated as a separate entity. According to Brown (1992), "when pronunciation teaching does appear, it is integrated into the language as a whole and not studied as a phenomenon divorced from the process of communication". Furthermore, as O'Connor (1980: 2) states, adults must create their sound system of the foreign language (FL) since the linguistic habits of the mother tongue are well established. This supports the idea that the instruction in phonology is necessary so that learners can receive effective training regarding "the education of the ear", which will make them able to understand the native utterance and to communicate orally with a minimum of intelligibility (Brown, 1992; Morley, 1994; Kenworthy, 1997; Munro \& Derwing, 1999; Hancock \& Pavón, 2005; Gimson, 2008).

Due to the fact that the differences between the Spanish and English sound system have a physiological explanation, the teacher should provide students with the required knowledge to identify the articulatory reasons why inaccurate approximations of new sounds are produced and, to avoid these potential errors in language production. To do so, the teacher must have a good command of the articulatory features of both the Spanish and English language. Thus, the teacher can offer all types of explanation about potential difficulties that occur once a comparison of the phonological systems is carried out.

It is worth training students to implement pronunciation activities since they are a crucial tool that enables students to store mental images of sounds and to become inteligible. For that reason, the suprasegmental elements of stress and rhythm are essential aspects to achieve intelligibility in the teaching of pronunciation due to the fact that several characteristics of the English language, especially the production of unstressed syllables (with most of them having reduced vowel sounds), may pose a problem to learners when they produce weak syllables not only in isolated words but also in connected speech. When these difficulties are overcome, learners become more intelligible (McNerney \& Mendelsohn, 1992; Walker, 2010; Cauldwell, 2013). 
In this study it is analysed the role that instruction plays on the part of two groups of Spanish students of English (the control and the experimental group) in the process of learning the phonology of a second language (English) This research was conducted in a bilingual setting corresponding to B1 level of Common European Framework of Reference for Languages (CEFR). In general terms, the aim is to identify a number of areas directly related to the effects that the use of specific instruction can produce to attain major achievements in the teaching-learning process. More specifically, the general objective of this study is to investigate whether the theoretical-practical instruction on pronunciation has a crucial impact on the vowel quality production of stressed and unstressed syllable in isolated words and in wider contexts, and therefore, in the improvement of intelligibility and of the oral production in general terms.

The specific objectives of this investigation are 1) to identify to what extent the assignment of the lexical stress determines the vowel quality production in stressed and unstressed syllables, 2) to determine the influence that the phonetic-phonological knowledge of learners may have in the production of vowel quality in stressed and unstressed syllables in isolated words; and 3) to determine the influence that the phonetic-phonological knowledge of learners may have in the production of vowel quality in stressed and unstressed syllables in longer sequences and in connected speech.

\section{Intelligibility and Vowel Quality in Stressed and Unstressed Syllables}

As Brown (1992) claims, "if intelligibility means the success with which a speaker conveys his message to the listener, then it is obviously a very important factor in pronunciation teaching as in all other aspects of ELT". When we talk about pronunciation, one of the most reocurring ideas is that the main goal when teaching pronunciation is to make learners intelligible. According to Kenworthy (1997), "when we set intelligibility as our goal, rather than native-like pronunciation, in practical terms this means we are aiming for something "close enough".

Due to the fact that the English language has become an international language, teachers need to highlight the fact that adult students speak both with native and non native speakers of the English language outside the classroom. Jenkins (2000), in her fundamental work about the necessity to regard English phonology according to the status of English as an international language, also points out the requirement of paying attention to the phonological features that are responsable for breakdowns in communication. Furthermore, she addresses a series of essential features in pronunciation that should be mastered to make sure that the speaker is understood. Jenkins (2002) labelled these pronunciation features as the 'Lingua Franca Core'. Teachers of English focusing on pronunciation should be aware of the fact that the goal to improve pronunciation for many adult learners is to attain mutual intelligibility instead of perfection.

According to Sifakis and Souragi (2005), quoted in Usó (2008), intelligibility means the ability to produce speech that is understood by the stakeholders within the given communicative framework. If the objective is to achieve intelligibility, then this means that some pronunciation features will be more important than others. To stress words and sentences is vital if some chunks of the message are highlighted and if the aim is to understand words correctly. Consequently, aspects such as vowel quality and stress patterns now get the attention they deserve after the rise of the current methodology that has produced a change towards a new way of teaching the pronunciation, clearly focused on achieving a communicative competence through meanigful activities (Burgess \& Spencer, 2000; Derwing \& Rossiter, 2003; Levis \& Grant, 2003; Lozano, 2005; McLaren, Madrid, \& Bueno, 2005; Usó, 2008; Walker, 2010; Cauldwell, 2013). Without an extensive and in-depth knowledge about vowel quality in stressed syllable and unstressed syllable, and further implementation of these phonetic-phonological aspects, speakers may not be able to produce intelligible utterances (Brown, 1992, McNerney \& Mendelsohn, 1992). This is particularly decisive to train bilingual teachers as the suprasegmental aspects are crucial from the point of view of meaning in the pronunciation of an utterance. Stressing the important information is closely related to the manipulation of meaning, the identification of the stress syllable and the production of the right quality in all the syllables are the pillars on which the interpretation of utterances stands (Valcke \& Pavón, 2015).

According to Martínez (2004), articulatory and auditory training should be conducted bearing in mind that this involves integrating the teaching of phonology within a wider context intended to enable communication. Only through the development of auditory skills and the teaching of an appropriate production of segmental and suprasegmental features will teachers provide their students with the ability to communicate effectively in a foreign language $(\mathrm{FL})$.

Finally, it is worth mentioning that it is widely believed that a good pronunciation will provide wider acceptance on the part of native speakers (Cortés, 2002), because it is regarded as the calling card for the society, as a good pronunciation deserves high praise and admiration. Otherwise, a defective pronunciation will require more 
attention on the part of the speaker, triggering weariness or the loss of patience. Furthermore, a bad pronunciation or a strong foreign accent may provoke a negative attitude of the counterpart or even the mockery since, as they are providing information about geographical and social identity (Laroy, 1995; Dalton \& Seidlhofer, 2000; Seidlhofer, 2001; Moyer, 2004; Dauer, 2005; Levis, 2005; Jenkins, 2005), they are not deprived of prejudice and stereotypes (Munro, 2003; Derwing et al., 2004).

\section{Research Methodology}

This study is not only an analytical research, where deductive and inductive elements are combined (Nunan, 1992), but also a quasi-experimental and quantitative research in its design and methodology. Likewise, this study is synthetic in nature "an approach to second language phenomena that allows us to view the separate parts as a coherent whole", Seliger and Shohamy (1989), since it studies and analizes a particular segmental and suprasegmental aspect, the vowel quality in stressed and unstressed, in two groups of students (the control and the experimental group).

\subsection{Context and Participants}

The group of learners chosen for the study were Spanish learners enrolled for the 1st year of the English Studies Bachelor's Degree at the University of Córdoba. The group consisted of 84 students, and was later split into two different ones: the experimental group and the control group. The group was originally larger, with apparently similar characteristics, but was reduced in order to obtain a greater homogeneity among their members. A procedure for the selection of the students was established, then, in order to assure that all of them possessed the same characteristics: the same age, the same period of time learning English and, above all, the same motivation as far as the interest in getting a good command of the English language was concerned. The selection process consisted of three phases: firstly, the learners answered a questionaire about their personal characteristics, aptitude and motivation; secondly, they took a standardised test in order to determine their level of English (those learners who showed a competence in English higher or lower than the B1 level were excluded); and thirdly, they were asked whether they gave their consent to take part in the study.

It is worth highlighting that there are not meaningful differences between the two groups as far as the questionnaire is concerned. They are adult learners whose native language is the Spanish language, and who are students of the English Studies Degree. There are more female than male among them and most of them started to study English in primary education. More than $50 \%$ had received some type of English language teaching at non-official institutions, and more than 50\% had never been to an English-speaking country. Most of them had learnt English through a traditional methodology based on the grammar-translation method or one similar, but only a low percentage had learnt English through a communicative methododology. In terms of their language skills, the majority possessed a higher command of the writing skill, an in general of the written ones over the oral skills, with listening exhibiting the lowest percentages. Their principal objectives are to become teachers of English or translators, to be able to interact with other language speakers, and to achieve a satisfactory level that might enable them to choose a profession in which a sound command of the English language is required. Also, they are students motivated to learn a FL, who usually listen to music, watch films and read books in English. Most of them believe they have an intermediate level, which neatly corresponds to the reality. They are interested in the culture and history of English-speaking countries, and they do not show a considerable linguistic ego. The participants are aware of their problems and constraints when they use the English language. They consider that having a good pronunciation is really important and that, through specific instruction based on the phonetic-phonological explanation, it is posible to improve some aspect (or all) of the pronunciation. Finally, although they have not received specific instruction in pronunciation, they are motivated since they foresee that the correct use of pronunciation will provide high benefits.

It goes without saying that in the English Studies Degree a wide variety of subjects are given for the study of different languages (English, Spanish, Italian, French, German and Arabic), but those of interest in the field of study are the subjects so-called "English Pronunciation I" that is offered during the first year of the first term and "English Pronunciation II" that is also offered during the first year but in the second term. The students of our study who received a pedagogic instruction, the experimental group, were those students that had received theoretical and practical instruction in pronunciation, both in the form of lessons mainly based on theoretical principles, and in the form of practical lessons in which they could work specifically on the areas tackled in the theory lessons. In contrast, the control group took the test without earlier instruction.

\subsection{Data Collection}

Being a quasi-experimental study where the previous knowledge of its nature is always reported as a beneficial assent, it was decided that it was advisable that the participants knew beforehand all the information related to 
the nature and objectives of the research. Likewise, we gained the consent of each participant to whom the utmost data confidentiality derived from the observation of their linguistic behavior was ensured.

For the data collection procedure, we designed a series of activities called tests of production where the variable that was measured was the ability to identify whether the participants could produce a correct stressed pattern in each isolated word, within the context of the sentence, or within the context of the text or letter.

Every test was divided into six activities in which the students had to pronounce a series of words and sentences paying special attention to the vowel quality of the stressed and unstressed syllable. The activities covered an overall number of 174 words (see annex I): three activities focused their attention on producing the vowel quality in unstressed syllables in minimal pairs of words (activity 1), in a series of isolated words (activity 4), and in a series of words within the text boundaries (activity 6). The activity 2 covered pronunciation aspects of the diphthong ea in different words where the vowel quality of the syllable in which this diphthong takes place was analysed. Finally, two activities dealt with the production of the vowel quality in stressed syllable either in minimal pairs of words (activity 3 ) or in the text boundaries (activity 5).

With the implementation of these activities we understand that it is possible to identify whether the participants are able to recognize and produce accurately the vowel quality of stressed and unstressed syllables in some cases, and in others to produce the appropriate stress pattern in each isolated word, everything within the context of the sentence or within the context of the text or the letter.

\subsection{Description of the Pedagogic Treatment}

The test was designed to include activities of production that, together with those of perception, are the two sides of the oral aspect of the language. The goal was to study whether formal instruction in phonology is regarded as a crucial factor to obtain better scores in the test. This production test was taken by students of the two groups: those participants of the experimental group, who had received a theoretical-practical pedagogic instruction about aspects of pronunciation and about phonetic-phonological symbols, and those participants who did not receive any instruction.

The theoretical-practical instruction that the learners of the experimental group received consisted of the following contents:

a) representation, perception and production of the English phonetic-phonological symbols along with the recognition of the vowel quality in stressed and unstressed syllables either in word boundaries and in connected speech boundaries;

b) description and practice of the nature and components of the accentuation of English;

c) levels of accentuation;

d) types of stresses;

e) characteristics and occurrence of stress patterns;

f) relationship between accentuation and meaning: word and sentence stress;

g) effects of lexical stress in the production and percepetion of communicative utterances;

h) typology of errors

\section{Results of the Study}

When comparing the results per activity between the experimental group after having received a theoretical-practical pedagogic instruction on pronunciation and the control group with no previous pedagogic instruction, the differences between the two groups are significant. After the instruction students in the experimental group committed less errors in absolute and relative terms in relation to the errors committed by the control group.

The differences between the two groups in relation to the average values and the average score of each activity of the test were analyzed. For this purpose the average values and the average score of the test are shown in the following figure: 


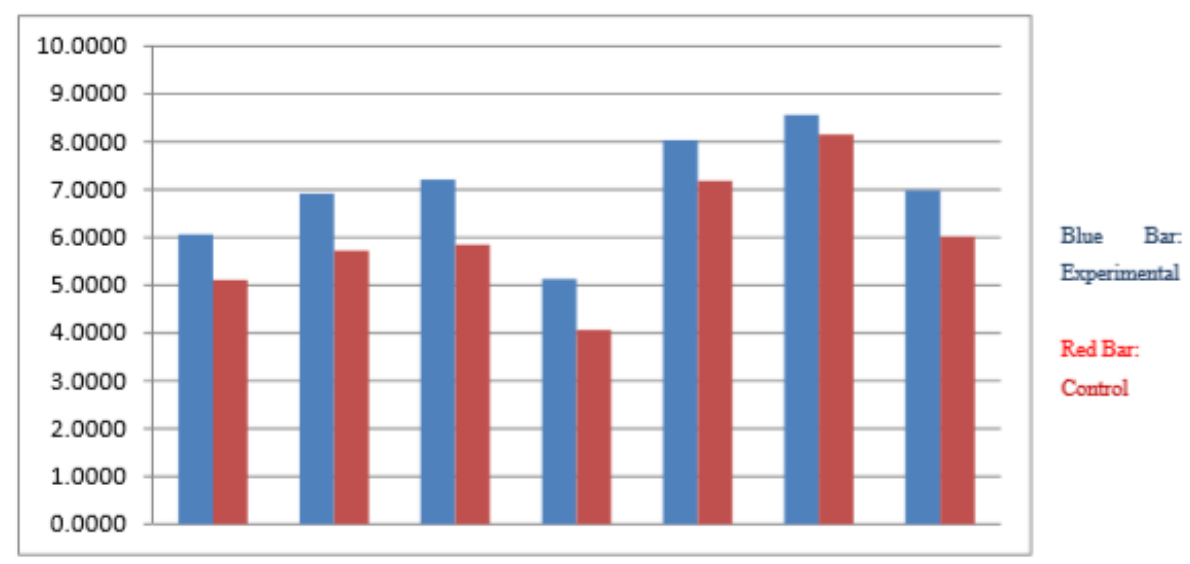

Question 1 Question 2 Question 3 Question 4 Question 5 Question 6 Average Score

Figure 1. Average values and average score of each test question

Figure 1 shows significant differences with reference to the average values obtained in the activities of each group. The bar coloured in blue shows the average test scores obtained by the experimental group. Meanwhile, the red bar shows the average test scores obtained by the control group. Once the study was completed, a series of conclusions could be drawn after comparing the results obtained by each group. Thus, we can see that whereas in the first activity, that focuses its attention on the production of the vowel quality in unstressed syllables in minimal pairs of words, the average score is 6,1 in the experimental group, the average score is 5.1 in the control group. In the second activity, that covered pronunciation aspects of the diphthong ea in different words where the vowel quality of the syllable in which this diphthong takes place was analysed, the average score is 6.9 in the experimental group whereas in the control group it is 5.7. This activity was difficult for both groups of learners and there are no major differences between both groups. In this case we can see a difference of 1 point and two tenths. In the third activity, dealing with the production of the vowel quality in stressed syllable in minimal pairs of words, the average score is 7.2 in the experimental group and 5.8 in the control group. The second group, as in all cases, had more problems than the experimental group since significant differences of 1 point and 4 tenths can be noted between both groups. In the fourth activity that focused their attention on the production of the vowel quality in a series of isolated words, the average score is 5.1 in the experimental group and 4.1 in the control group. In the fifth activity that dealt with the production of the vowel quality in stressed syllable either in the text boundaries, the average score is 8 in the experimental group whereas it is 7.1 in the control group. In this activity a significant difference of 1 point can be observed in favour of the experimental group. In the sixth activity that focused their attention on producing the vowel quality in a series of words within the text boundaries, the average score is 8.5 in the experimental group whereas it is 8.1 in the control group. A global comparison of the scores from the experimental and control group in the six activities, a final mark of 6.9 in the experimental group and a final mark of 6 in the control group with a difference of 9 tenths, allows us to assert that there is a contrast of performance between the two groups. Even though the difference may not be very high, there is a clear tendency between the average scores obtained by the experimental group and the control group and, therefore, a visible distance can be shown between the results obtained in each one of these series of activities in both groups, with a less amount of mistakes committed by the experimental group as compared to those committed by the control group.

As for the activities that the learners of both the experimental group and the control group considered more difficult, it is worth highlighting activity 6 as it deals with measuring the vowel quality variable. In this activity the percentage of words (with error) which the subjects of the study committed is the highest.

Then, each activity results of the experimental group and control group are compared. 
Table 1. Factorial analysis of variance in the test

\begin{tabular}{lllll}
\hline Groups & Recount & Sum & Average & Variance \\
\hline Experimental & 36 & 251,41842 & 6,983845 & 0,23179339 \\
Control & 72 & 432,896292 & 6,012449 & 0,42553796 \\
\hline
\end{tabular}

Table 2. Factorial analysis of variance in the test

\begin{tabular}{lllllll}
\hline $\begin{array}{l}\text { Source } \\
\text { variances }\end{array}$ & $\begin{array}{l}\text { of } \begin{array}{l}\text { Sum } \\
\text { squares }\end{array} \\
\text { Between groups }\end{array}$ & 22,6466677 & 1 & $\begin{array}{l}\text { of Level } \\
\text { freedom }\end{array}$ & $\begin{array}{c}\text { of Average } \\
\text { squares }\end{array}$ & $\begin{array}{l}\text { of } \\
\text { Statistical F Probability }\end{array}$ \\
\hline Within the groups & 38,3259638 & 106 & 0,6466677 & 62,6350009 & $2,57 \mathrm{E}-12$ & 3,93069167 \\
Total & 60,9726315 & 107 & & & & \\
\hline
\end{tabular}

In this summary the comparison between the data of the experimental group and the control group is presented. The experimental group consisted of 36 subjects, whereas the control group consisted of 72 subjects. A significant imbalance is identified in terms of the subjects that carried out the test as part of the experimental group compared to the number of learners who took the text as part of the control group. The learners' attrition in the experimental group, that is, the loss of subjects throughout the study due to weariness, boredom, illness or lack of geographical mobility is irrelevant and has not affected the data. The total number of errors committed by the subjects of study in each group shows a global figure of 251,41842 errors in the experimental group, whereas a total of 432,896292 errors were commited by the control group. The average score obtained in the test by each group is 6,9 points in the experimental group and 6 points in the control group. Finally, the variance that is the average of the squared distances data in relation to the average, is used to give some understanding of the variance that is produced in the errors committed by the learners. A smaller variance means that a more homogeneous behabiour of the subjects occurred in terms of the number of errors.

If the analysis of variance is observed, we can state that there is again a significant difference between the two groups (series) since $\mathrm{F}$ (analysis of variance $\mathrm{F}$ statistics) is higher than the critical value for $\mathrm{F}$.

\section{Discussion of Findings}

This section answers questions in accordance with the proposed objectives. With regard to the proposed general objective, data show that: a) the specific instruction (theoretical-practical) on a highly specific element such as the vowel quality in stressed syllable and unstressed syllable improves its production; $b$ ) this improvement has an overall effect on the achievement of a more accurate pronunciation and, in particular, on the achievement of intelligibility since the elements are an essential component for the understanding of messages; c) the test has measured what could be labelled as the "microlevel" of pronunciation (isolated words) and the "macrolevel" (sentences and longer texts).

In the same vein as traditional approaches have frequently suggested, O'Connor (1991) and Gimson (2008) among others, believe that the first step in the teaching of pronunciation is to deal with isolated sounds, that is, vowel and consonant sounds; then, the second step should be to analyse the processes that affect segments in connected speech; and finally, the prosodic elements, that is, the stress, rhythm and intonation should be tackled. However, it has been put forward that the non segmental features of stress, rhythm, tone, intonation and general articulatory contexts may be decisive factors in order to acquire a nearly native segmental phonology, whereas they are less decisive to achieve a total discursive and social competence (Pennington et al., 1990; Pennington \& Richards, 1986). According to McNerney and Mendelsohn (1992: 186), Brown (1994), Hancock and Pavón (2005) and Gimson (2008), specific treatment of stress patterns and accentuation in general conveys a positive experience because this suprasegmental aspect helps learners improve their understanding and achieve the objectives pursued even in a situation determined by a short period of instruction.

Since accentuation has a major effect on communication, it must receive an earlier treatment than the one given to isolated sounds. This does not mean that the segmental aspects should be left behind but that they should not be the initial aspect to cope with in the teaching process of a foreign language, especially in English. The segmental aspects in isolated words, in wider sequences and in connected speech, depend on the assignment of the word and sentence stress. Thus, an incorrect assignment of the word and sentence stress causes the use of 
strong forms instead of weak forms and viceversa, and the lack of vowel reduction in unstressed syllables.

Also, due to the fact that interference processes in the acquisition of a foreign language prevail in the first stages, the prosodic interference will prevail in the first stages of acquisition. Therefore, as James and Leather (1987) stated, a lot of segmental processes that take place in the acquisition of a foreign language are the direct result of the prosodic interference; e.g. many Spanish speakers fail at reducing the unstressed syllables in English utterances. As these learners gradually master the stress and rhythm, they can overcome these tendencies.

Due to the fact that the learners of the experimental group, who received a programme of specific instruction, obtained better results than the learners of the control group, it may be concluded that the theoretical-practical instruction can be a useful tool for improving the learning cognitive processes, and, therefore, that the teaching of elements associated with the production of accentuation has a positive influence on the production of the vowel quality in stressed and unstressed syllables in isolated words.

Thanks to the phonetic-phonological knowledge acquired by the learners of the experimental group, they were able to identify the lexical function of the stress whereby the stress location in a word can be used for distinguishing the meaning of a word. Likewise, this knowledge helps them identify the role of the stress to highlight some words as especially important within the sentence. These words usually are "nouns, adjectives, demonstratives and interrogative pronouns, main verbs and adverbs" (Jones, 1960), that is, those words that normally refer to lexical or content words, whereas the gramatical or functional words are unstressed.

In our opinion, and in accordance with what Taylor (1993) claims, the learners of the experimental group recognise the stress pattern of a word so they can predict more sucessfully the characteristics of the vowels that in this situation are used. This is essential because learners often learn new words in written form, and as a result they cope with challenging tasks to try to guess the vowel quality through spelling. On the other hand, learners can also benefit from the findings that are a result of the opposite stance, that is, if they know the assignment of reduced and non reduced vowels in words, they will be able to determine its stress pattern easily. As a result of this explanation, it is important to establish a relationship between the vowels and the stress patterns within words that describe firstly aspects individually and then interdependently.

These findings run along with the majority of experts, for example, according to Martínez (2004), only through the teaching of the correct production of segmental and suprasegmental features, our students can learn the ability to communicate in a foreign language successfully.

The use of the formal instruction in pronunciation helps learners improve the production of sounds, in that case, vowels (segmental element) in stressed and unstressed syllables (suprasegmental element) both in words and in wider sequences and in connected speech. This particular assumption is clearly shown in the comparison between the subjects of the experimental and control groups. The former received a formal instruction in pronunciation before taking the test, whereas the latter received no previous instruction. In general, the results of the test in both groups showed the crucial importance given to the instruction for learning a foreign language.

\section{Conclusions}

As a general conclusion, the analysis of the findings indicate that the teaching of the English language must grant an essential role to the teaching of pronunciation and, in particular, to the teaching of those aspects of pronunciation (English accentuation and vowel quality), which are crucial to achieve different degrees of intelligibility in oral communication.

Due to the lack of consistency in the English language in relation to the correspondence between grapheme-sound, a characteristic which affects dramatically the acquisition of communication in the English classroom, it is required that Spanish learners are initiated by teachers in the implementation of a formal pedagogic instruction in pronunciation where the aspects of accentuation and vowel quality play key roles. These elements are responsible for the correct correlation between the vowel graphemes and sounds in a word, and determine that the sounds are pronounced and represented by the correct letter.

In accordance with the results obtained we can suggest that, in order to be able to achieve intelligibility it is necessary to give priority to the accentuation elements because the stress pattern of words must be correctly assigned previously to the production of the vowel quality element. Due to the treatment of these elements in the English classroom, the Spanish learners of the English language have achieved an improvement in their communicative abilities and have become more inteligible as far as the recognition and production of words and statements in the English language are concerned.

In addition, we may conclude that there is a clear and direct relationship between the formal instruction on pronunciation and the production of vowel quality in stressed and unstressed syllables. This is closely related to 
what Dalton and Seidlhofer (2000: 73) state as they assert that an incorrect assignment of the word stress leads to errors related to the use of strong forms instead of weak forms or viceversa, and to the lack of vowel reduction in unstressed syllables, which inevitably causes negative results with regard to the achievement of intelligibility.

Furthermore, as Dalton and Seidlhofer (2000) highlight, in connected speech the listener uses the stressed syllable as a reference point to identify the word in its mental lexicon. This leads us to affirm that it is, first, the correct assignment of stressed syllables and, then, the correct production of sounds which determines that the auditory stimuli can be stored adequately in connected speech, a conclusion extensively supported by scientific literature (Kenworthy, 1997; O'Connor, 198; Pennington, 1996; Celce-Murcia, Brinton, \& Goodwin, 1996; Pavón, 2000). McCarthy (1978) describes as essential the treatment of problems derived from vowel and consonant phonemic mistakes. He also hightlights that priority problems are those related to the incorrect assignment of the word and sentence stress, and the lack of vowel reduction in unstressed syllables is as problematic for communication as the use of strong forms instead of weak forms.

Following the findings of our study, it is suggested that a formal instruction on pronunciation will help students acquire a better knowledge of all the phonetic-phonological features associated with the English accentuation, help create a more accurate mental image of the vowel executions that appear in stressed and unstressed positions; and, therefore, help improve the ability to identify and produce them. This improvement is produced not only in isolated words but also in wider sequences such as sentences and short oral texts since the oral communication is mainly connected speech.

To sum up, in the process of providing an efficient teaching of the English language and matching the particular necessities that oral communication exhibits in this particular language, teachers should be aware of the relevance of providing an adequate instruction in the area of pronunciation. More specifically, teachers should tackle the area of pronunciation emphasizing the importance of the accentuation elements and of vowel quality aspects. They definitely become priority elements to comply especially for Spanish learners of the English language, since the majority of the problems they have when producing words and statements in English are produced by the phonological nature as the Spanish language. And finally, it is worth emphasizing that the suprasegmental aspects of the English language have a greater influence in overall communication than the segmental aspects, and therefore teachers should pay more attention to them in the teaching of English pronunciation. This change of paradigm also implies a step forward in the specific research in the area of pronunciation, since with the rise of the communicative approach; the suprasegmental aspects of accentuation have reached the status of a decisive element. In addition, research has shown that the production and recognition of vowel quality in stressed and unstresed syllables play a decisive role in the achievement of intelligibility.

The degree of innovation lies in the priority given to suprasegmental aspects over segmental aspects, as the traditional approaches consider both dimensions equally important for achieving intelligibility. The suprasegmental aspects are crucial in pronunciation since they work on the syllable and the sounds that constitute the syllables and subsequently, the words. These aspects must be used thoroughly since they are closely related to the meaning, and they are the turning point for the interpretation of messages in statements (Valcke and Pavón, 2015). It should be noted, also, that the correct use of the suprasegmental features related to accentuation and the production of vowel quality is not only relevant in the field of teaching English as a foreign language, but it is an essential area to train future teachers in the area of bilingual education. It is during the process of conveying academic content meaning through a foreign language when the attainment of intelligibility becomes paramount for both teachers and students. In this context, specific training on how to use the language in a comprehensible way will have a direct impact on the quality of teaching and learning process.

It must be noted that this study focuses on students' capacity to incorporate explicit knowledge in their ability to discriminate and produce vowel quality in stressed and unstressed syllables and therefore is limited in the sense that it does not address the subsequent transfer of this knowledge into oral production. In the activities that the students had to perform, the oral production of the subjects of study is not reflected, but rather their linguistic competence about the vowel quality in stressed and unstressed syllables in words, wider sequences and connected speech. For this reason this paper could be considered the starting point for another study which would measure the capacity of learners' oral production. Another characteristic of the present study is that it was conducted with subjects under the same conditions in a real situation of teaching practices (the independent variable), the specific treatment being the main source of variation (dependent variable) to the same group.

\section{References}

Brown, A. (ed.) (1992). Approaches to Pronunciation Teaching. Londres: MacMillan Publishers Limited. 
Brown, H. D. (1994). Principles of language learning and teaching. Englewood Cliffs, Nueva York: Prentice-Hall.

Burgess, J., \& Spencer, S. (2000). Phonology and Pronunciation in Integrated Language Teaching and Teacher Education. System, 28, 191-215. https://doi.org/10.1016/S0346-251X(00)00007-5

Cauldwell, R. (2013). Phonology for Listening: Teaching the Stream of Speech. Birmingham.

Celce-Murcia, N., Brinton, M. D., \& Goodwin, J. M. (1996). Teaching Pronunciation: A Reference for Teachers of English to Speakers of Other Languages. Cambridge, Nueva York: Cambridge University Press.

Cortés, M. (2002). Didáctica de la prosodia del español: la acentuación y la entonación. Madrid: Edinumen.

Dalton, C. and Seidlhofer, B. (2000). Pronunciation. Oxford: Oxford University Press.

Dauer, R. (2005). The lingua franca core: A new model for pronunciation instruction? TESOL Quarterly, 39, 543-550. https://doi.org/10.2307/3588494

Derwing, T. M., \& Rossiter, M. J. (2003). The effects of pronunciation instruction on the accuracy, fluency, and complexity of L2 accented speech. Applied Language Learning, 13, 1-17.

Derwing, T. M, Rossiter, M., Munro, M., \& Thomson, R. (2004). Second language fluency: Judgements on different tasks. Language Learning, 54, 655-79. https://doi.org/10.1111/j.1467-9922.2004.00282.x

Gimson, A. C. (2008). Gimson's Pronunciation of English. (7th ed.). Londres: Edward Arnold.

Hancock, M., \& Pavón, V. (2005). Tonic stress. Underlining with your voice. TESOL-Spain Newsletter, 30, 22-23.

James, A., \& Leather, J. (1987). Sound Patterns in Second language Acquisition. Dordrecht: Foris Publications.

Jenkins, J. (2000). The Phonology of English as an International Language. Oxford: Oxford University.

Jenkins, J. (2002). A sociolinguistically-based, empirically-researched pronunciation syllabus for English as an international language. Applied Linguistics, 23, 83-103. https://doi.org/10.1093/applin/23.1.83

Jenkins, J. (2005). Implementing an international approach to English pronunciation: The role of teacher attitudes and identity. TESOL Quarterly, 39, 535-543. https://doi.org/10.2307/3588493

Jones, D. (1960). An Outline of English Phonetics. Cambridge: Cambridge University Press.

Kenworthy, J. (1997). Teaching English Pronunciation. Harlow: Longman.

Laroy, C. (1995). Pronunciation. Oxford: Oxford University Press.

Levis, J., \& Grant, L. (2003). Integrating pronunciation into ESL/EFL classrooms. TESOL Journal, 12(2), 13-19. https://doi.org/10.1002/j.1949-3533.2003.tb00125.x

Levis, J. (2005). (ed.). TESOL Quarterly Special Issue: Reconceptualizing pronunciation in TESOL: Intelligibility, World Englishes, and Identity.TESOL Quarterly, 39(3), 365-572.

Lozano, R. (2005). Sobre el vocalismo y la pronunciación. Laboratorio de fonética aplicada. Phonica, 1, 1-17.

Martínez, F. (2004). Estudio de una intervención pedagógica para la enseñanza de la pronunciación inglesa en $4^{\circ}$ curso de la E.S.O. Tesis Doctoral. Universidad de Murcia.

McCarthy, P. (1978). The Teaching of Pronunciation. Cambridge: Cambridge University Press.

McLaren, N., Madrid, D., \& Bueno, A. (2005). TEFL in Secondary Education. Granada: Universidad de Granada.

McNerney, M., \& Mendelsohn, D. (1992). Suprasegmentals in the Pronunciation Class: Setting Priorities". En P. Avery y S. Ehrlich Teaching American English Pronunciation. Oxford: Oxford University Press, págs. 185-196.

Morley, J. (1994). Pronunciation Pedagogy and Theory: New Views, New Directions. Alexandria (Virginia): Teachers of English to speakers of other languages.

Moyer, A. (2004). Age, Accent and Experience in Second Language Acquisition. An Integrated Approach to Critical Period Inquiry. Clevedon: Multilingual Matters. https://doi.org/10.21832/9781853597190

Munro, M. J., \& Derwin, T. M. (1999). Foreign Accent, Comprehensibility, and Intelligibility in the Speech of Second Language Learners. Language Learning, 49, 285-310. https://doi.org/10.1111/0023-8333.49.s1.8

Munro, M. J. (2003). A primer on accent discrimination in the Canadian context. TESL Canada Journal, 20, 
38-51. https://doi.org/10.18806/tesl.v20i2.947

Nunan, D. (1992). Research Methods in Language Learning. Cambridge: Cambridge University Press.

O'Connor, J. D. (1980). Better English Pronunciation. Cambridge: Cambridge University Press.

O'Connor, J. D. (1991). Phonetics. Harmondsworth: Penguin.

Pavón, V. (2000). La enseñanza de la pronunciación del inglés. Granada: Granada Lingüística.

Pennington, M., \& Richards, J. (1986). Pronunciation Revisited. TESOL Quarterly, 20, 207-226. https://doi.org/10.2307/3586541

Pennington, B. F., Van Orden, G. C., Smith, S. D., Green, P. A., \& Haith, M. M. (1990). Phonological processing skills and deficits in adult dyslexics. Child Development, 61, 1753-1778. https://doi.org/10.2307/1130836

Pennington, M. C. (1996). Phonology in English language teaching. Londres: Longman.

Seidlhofer, B. (2001). Pronunciation. En Carter y Nunan (editores), The Cambridge Guide to Teaching English to Speakers of other Languages (pp. 56-65). Cambridge University Press. https://doi.org/10.1017/ CBO9780511667206.009

Seliger, H., \& Shohamy, E. (1989). Second Language Research Methods. Oxford: Oxford University Press.

Taylor, L. (1993). Pronunciation in Action. Prentice Hall International.

Usó Viciedo, L. (2008). La enseñanza de la pronunciación en LE: Algunas consideraciones a tener en cuenta. Phonica, 4, 104-130.

Valcke, J., \& Pavón, V. (2015). A comparative study on the use of pronunciation strategies for highlighting information in university lectures. In R. Wilkinson, \& M. L. Walsh (Eds.), Integrating Content and Language in Higher Education: From Theory to Practice (pp. 323-341). Frankfurt-am-Main: Peter Lang.

Walker, R. (2010). Teaching the pronunciation of English as a Lingua Franca. Oxford: Oxford University Press.

\section{Appendix. Test production}

Activity 1. Pronounce the following pairs of words and pay attention to the pronunciation of the vowel quality in unstressed syllable.

1 starlight / starlet

2 lettuce / figure

3 cabbage / colour

4 grandson / Jackson

5 peaches / paper

6 violate / violet

7 teaches / sugar

8 sunglass / Douglas

9 orange / woman

10 simulate / chocolate

11 market/sofa

12 begin / letter

13 saline / salad

14 music / support

Activity 2. Pronounce the following words and pay attention to the pronunciation of the vowel quality in the dipthong 'ea'.

spread, steak, unhealthy, earth, fear, head, hear, heart, learn, read, pear, wear, dead, deal, instead, appear, bear, beat, bread, break, creak, death, dealt, earring, jealous, neatly, nuclear, please, pleasure, scream 
Activity 3. Pronounce the following pairs of words and pay attention to the pronunciation of the vowel quality of the underlined syllable.

1 admire - admirable

2 amplify - amplifier

3 comfort - comfortable

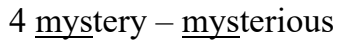

5 advantage - advantageous

6 agriculture - agricultural

7 prefer - preferable

8 medicine - $\underline{\text { medicinal }}$

9 industry - industrious

10 percent - percentage

11 electric - electrical

12 regret- regretful

13 disaster - disastrous

14 beauty - beautify

15 absentee

16 refugee

17 engineer

18 Nepalese

19 cigarette

20 mountaineer

Activity 4. Pronounce the following words and pay attention to the pronunciation of the vowel quality in the underlined unstressed syllables.

permit (n), tattoo, lifeless, testament, exxert (v), vaccinate, emptiness, extremist, brigade, comfortable, entrance, parade, centigrade, lagoon, expenditure, systematically, inspector, canoe, violate, objector, profitable, talented, depressed, stubborn, ambitious, confident, generally, broadband, delete, tornado, lightning, reliable, allergy, conference, audition, lonely, repetitive, challenging, enjoyment, jubilee, politics, preferable, protective, dependence, pollute, appear, pleasure, solace, cassette, civilian, invalid (n.), quivering, paragon, salon, obstruct, vestige, pullover, nurture, preview, military, commune (n), ushered, allure, hostel, hotel, fortnight

Activity 5. Pronounce the following words and pay attention to the pronunciation of the vowel quality in the underlined stressed syllables.

1 I got my first record as a present when I was eleven.

2 You've progressed well this year, but I'd like to see even more progress.

3 We import too much petrol and the country's export figures are going down.

4 It started as a student protest, but now the army has rebelled against them.

$5 \mathrm{In}$ the desert, there is a big contrast between temperatures in the day and at night.

6 These companies produce household objects such as fridges and washing machines.

7 I couldn't accept their decision because I didn't understand the diagram. 
$8 \mathrm{He}$ gave his consent to put the minute painting in the corridor.

Activity 6. Read the following letter and analyse and produce the vowel quality of the unstressed syllable in the underlined words.

1 Dear Nigel,

Thanks for your letter. It was great to hear from you and to know that you are having a good time in China!

2 I am studying English in the United States at the moment. I am staying with a very hospitable family in Miami. They take me to lots of exciting places.

3 Life here is very interesting, although it's very different to home. I'm getting used to things now.

4 I still miss German food: the food here is tasty, but it's incredibly boring and - lots of hamburgers!

5 Miami is a really lively city, though it's very hot; I miss good old German rain sometimes! Still, the beaches are excellent and I'm even learning to surf!

$6 \mathrm{Ok}$, I've got to go now. Write soon and tell me about life in China.

Love, Anna

\section{Copyrights}

Copyright for this article is retained by the author(s), with first publication rights granted to the journal.

This is an open-access article distributed under the terms and conditions of the Creative Commons Attribution license (http://creativecommons.org/licenses/by/4.0/). 